\title{
The Emerging Role of Inhibitor of Growth 4 as a Tumor Suppressor in Multiple Human Cancers
}

\author{
Shiyun Cuia Yanping Gao ${ }^{b}$ Kai Zhang ${ }^{b}$ Jing Chen ${ }^{b}$ Rui Wang ${ }^{b}$ Longbang Chen ${ }^{b}$ \\ ${ }^{a}$ Department of Oncology, The First Affiliated Hospital of Nanjing Medical University, ${ }^{b}$ Department of \\ Medical Oncology, Jinling Hospital, School of Medicine, Nanjing University, Nanjing, Jiangsu, People's \\ Republic of China
}

\section{Key Words}

Inhibitor of growth $4 \cdot$ Proliferation $\cdot$ Invasion $•$ Chromatin $•$ Angiogenesis

\begin{abstract}
Inhibitor of growth 4 (ING4), a member of the conserved ING family, has been identified as an important tumor suppressor since it plays a critical role in the regulation of chromatin modification, cell proliferation, angiogenesis and cell migration. Some observations suggest that ING4 acts as a key regulator of tumorigenesis through modifying gene transcription in part by regulating the transcription factors p53 and NF-kappaB (NF-kB). However, these models have yet to be substantiated by further investigations. Numerous reports describe the reduced expression of ING4 in cancers, and the responsible mechanisms are involved in gene deletion, mutation, transcriptional and post-transcriptional dysregulation. This review aims to summarize the recent published literature that investigates the role of ING4 in regulating tumorigenesis and progression, and explore its potential for cancer treatment.
\end{abstract}

\section{Introduction}

Copyright (C) 2015 S. Karger AG, Basel

Inhibitor of growth (ING) family proteins are evolutionary conserved in all eukaryotes and have been regarded as important tumor suppressors. Comparison to genomes of other organisms revealed that the ING family is highly conserved from yeast to humans, suggesting it is involved in critical biological processes [1]. In human and mouse, it consists of five members, namely ING1 to 5. In yeast, Yng1, Yng2, and PHO23 are identified as three ING orthologues [2]. ING1 was first identified as a candidate tumor suppressor in subtractive 
hybridization assays with normal and tumor breast cells and subsequently linked to p53 $[3,4]$. Overexpression of ING1 could lead to G1/S arrest, while suppression of ING1 promoted transformation in vitro and tumor formation in vivo [3]. Since the discovery of ING1, four additional ING family members with homologous sequence, ING2-5, have been identified in humans [5-7]. ING proteins have been implicated in chromatin modifications and gene transcription through association with histone acetyltransferase (HAT) or histone deacetylase (HDAC). They are also shown to bind with and regulate $\mathrm{p} 53, \mathrm{NF}-\kappa \mathrm{B}$, and HIF-1a activity, modulating multiple cellular processes including cell cycle regulation, apoptosis and senescence [8]. In addition, ING1 and ING2 are involved in regulation of DNA replication and DNA repair [9-12]. Therefore, ING family has attracted increasing attention for its potent tumor-suppressive function. ING4, identified by computational homology search, is a novel member of ING family. Reduced expression or dysregulation of ING4 is widely found in cancers, and however, the underlying mechanisms are still poorly understood. This review aims to summarize the current knowledge on ING4 protein structure, tumor suppressive functions, status in cancers and the underlying molecular mechanisms, and explore its prospects of clinical application.

\section{Genomic Organization}

ING family consists of five members, some of which harbor several exons and therefore can be alternatively spliced into different splice variants, conferring more diversity to ING family functions. The five ING genes are located on five different chromosomes, and they are all close to the telomere/subtelomere region except ING3. The ING4 gene is located at chromosome 12p13.31. The original ING4 (ING4_v1) was identified by computational homology search and eight splice variants of ING4 have been discovered so far [13-15]. However, the roles of each endogenous variant are still unclear. ING4_v1 encodes a complete nuclear localization signal (NLS), whereas the ING4_v2 (a 3-bp skip form), ING4_v3 (a 9-bp skip form), and ING4_v4 (a 12-bp skip form) lack 1, 3, and 4 amino acids in the NLS, resulting in increased cytoplasmic localization of these proteins [13, 16, 17] (Fig. 1). The ING4_v4 lacking of four amino acids (KGKK) was initially regarded as genomic deletions in human cancer cell lines [18], but now it is now accepted that it represents a natural splicing variant $[13,14]$. Additional four novel ING4 variants respectively lacking exons 2,3 and 6 are named ING4- $\Delta \mathrm{Ex} 2,-\Delta \mathrm{Ex} 3,-\Delta \mathrm{Ex} 6 \mathrm{~A}$ and $-\Delta \mathrm{Ex} 6 \mathrm{~B}[14]$.

\section{Protein Structure}

ING proteins contain several highly conserved regions, and many of them have been shown to be essential for ING proteins functions. The plant homeodomain (PHD)-like zincfinger domain is the most conserved region located in the C-terminus of ING proteins, which has been implicated in chromatin remodeling through interacting with specific nuclear protein partners [19]. Moreover, the PHD finger of ING proteins has been found to bind to H3K4me3 (the trimethylated lysine 4 residue of histone H3) [20, 21], a hallmark of active genes preferentially in sharp peaks at or immediately upstream of transcription start sites (TSS) [22], supporting the role of ING proteins in regulating chromatin structure and controlling transcriptional activity.

The nuclear localization sequence (NLS) is also a highly conserved region located upstream of the PHD. The nucleolar targeting signals (NTS) within the NLS mediated localization of p33ING1b to the nucleolus in response to UV-induced DNA damage [23]. However, the NTS motifs are not complete in ING3 to ING5 [1], suggesting the ability of nucleolus targeting may be compromised in these isoforms. In addition, NLS is also essential for ING4 nuclear localization and interaction with p53 [16].

\section{KARGER}


Fig. 1. Schematic structure of ING4 gene and protein. ING4 harbors eight exons. ING4_v2 to ING4_v4 vary from ING4_v1 at the exon 4 and 5 boundaries. ING4_v1, enrolled as the original ING4, encodes a complete NLS whereas the ING4 v2, ING4_v3, and ING4_v4 lack nucleotides 392-394, 383-391, and 383-394, respectively. The 12 nucleotides 379-390 encodes a sequence of four highly charged amino acid residues (KGKK) which are part of a nuclear localization signal in ING4. The red squares show $9 \mathrm{bp}$ donated by exon 4 , and the oringe squares show 3 bp donated by exon 5. $(\mathrm{NCR}=$ Novel Conserved Region; NLS = Nuclear Localisation Signal; PHD = Plant HomeoDomain; LZL = leucine zipper-like).

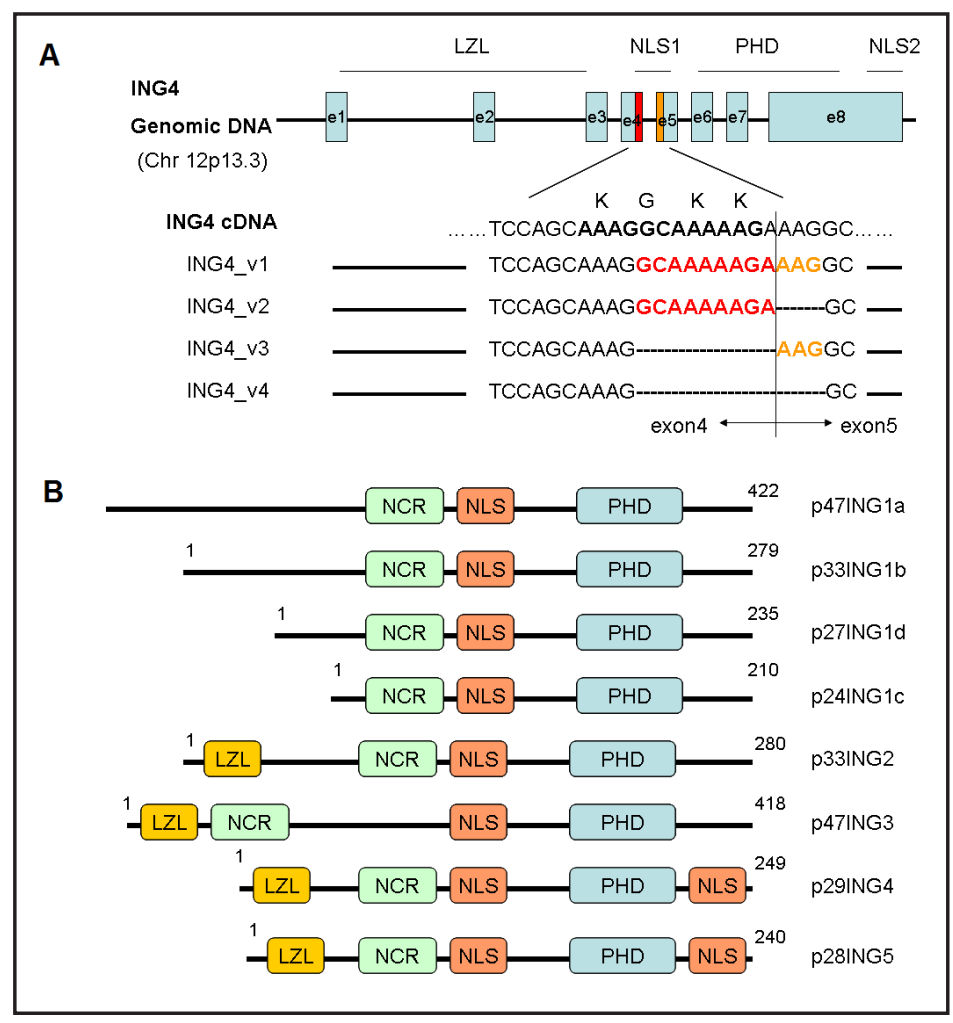

Additional conserved regions widely shared among the ING proteins include the novel conserved region (NCR) and the leucine zipper-like (LZL) motif. However, their functions are still largely unknown. NCR was also named Lamin Interaction Domain (LID) because of its capacity of interaction with lamin A for ING1-4 but not ING5 [24]. LZL motif is located at the N-terminus of ING2 to ING5, suggesting the potential ability of ING proteins to bind other leucine zipper-containing proteins, such as transcription factors [1]. LZL was required for the proper functions of ING2 in DNA repair, apoptosis and chromatin remodeling after UV irradiation [25], but it is not clear whether LZL play a similar role in ING4.

ING4 forms coiled-coil homodimers through its N-terminal domain while the NLS behaves as a disordered random coil and the two PHD fingers in the C-terminus independently bind to H3K4me3 histone marks. The LZL motif located at the N-terminus of ING4 may mediate its dimerization [26].

\section{Dysregulation of ING4 in tumors and the possible mechanisms}

Decreased expression of ING4 is frequently found in multiple cancers, including head and neck squamous cell carcinomas, hepatocellular carcinoma, gastric adenocarcinoma, ameloblastoma, astrocytomas, lung cancer, breast cancer and colorectal cancer, and is often correlated with poor prognosis [27-38] (Table 1). Especially, ING4 reduction was more prevalent in HER2-positive breast cancer, indicating that ING4 deletion might contribute to the HER2-driven breast cancer formation and growth [33]. Furthermore, ING4 as well as other biomarkers such as Cul1 (Cullin 1) and BRG1 (Brahma-related gene-1) could aid in the discrimination of melanoma from dysplastic nevi [39], suggesting the promising value of ING4 for cancer diagnosis.

Although the exact mechanisms have not been completely elucidated, recent investigations have uncovered some factors responsible for the ING4 downregulation. Deletion of chromosome 12p12-13 region, where ING4 is located, has been described in various cancers, accompanied with loss of some well-known tumor suppressor in addition 
Table 1. ING4 status in human cancers and its correlation with clinicopathological features and prognosis of cancer patients

\begin{tabular}{|c|c|c|c|c|c|c|}
\hline Cancer types & $\begin{array}{l}\text { Technique for } \\
\text { detection }\end{array}$ & Status & Frequency & $\begin{array}{l}\text { Clinicopathological } \\
\text { features }\end{array}$ & Prognosis & Ref. \\
\hline Ameloblastoma & $\begin{array}{l}\text { Microsatellite } \\
\text { Marker }\end{array}$ & $\begin{array}{l}\text { loss of } \\
\text { heterozygosity } \\
(\mathrm{LOH})\end{array}$ & $11 / 29(37.9 \%)$ & & & {$[30]$} \\
\hline Astrocytomas & $\mathrm{IHC}$ & Downexpression & $21 / 101(20.8 \%)$ & p65 expression & & {$[31]$} \\
\hline \multirow[t]{4}{*}{ Breast cancer } & $\mathrm{IHC}$ & Downexpression & $77 / 227(34 \%)$ & & DFS & [37] \\
\hline & $\begin{array}{l}\text { RT-PCR, WB, } \\
\text { IHC }\end{array}$ & downexpression & $38 / 60(53.3 \%)$ & microvessel density & & [76] \\
\hline & ISH & downexpression & $863 / 1033(83.5 \%)$ & $\begin{array}{l}\text { HER2/neu receptor } \\
\text { expression; }\end{array}$ & $\begin{array}{l}\text { no } \\
\text { influence } \\
\text { on survival }\end{array}$ & [33] \\
\hline & $\mathrm{CGH}$ & $\begin{array}{ll}\text { Gene } & \text { locus } \\
\text { deletion } & \end{array}$ & $10 \%-20 \%$ & & & {$[18]$} \\
\hline \multirow[t]{3}{*}{ Colorectal Cancer } & RT-PCR, WB & downexpression & $36.7 \%$ & microvessel density & & {$[75]$} \\
\hline & $\mathrm{IHC}$ & downexpression & $26.7 \%$ & & & \\
\hline & $\mathrm{IHC}$ & downexpression & $25 / 97(25.8 \%)$ & $\begin{array}{l}\text { Dukes' stages, } \\
\text { lymphatic metastasis }\end{array}$ & & {$[34]$} \\
\hline Gastric & RT-PCR & downexpression & $30 / 40(75 \%)$ & Tumor stage & & {$[28]$} \\
\hline \multirow[t]{7}{*}{ Carcinoma } & Q-PCR & downexpression & $13 / 13(100 \%)$ & & & \\
\hline & IHC & downexpression & $29 / 40(72.5 \%)$ & & & \\
\hline & IHC & downexpression & $99 / 120(92.5 \%)$ & & & \\
\hline & $\mathrm{IHC}$ & downexpression & $25 / 41(60.9 \%)$ & $\begin{array}{l}\text { tumor size, mitotic } \\
\text { index, tumor necrosis, } \\
\text { invasion, recurrence } \\
\text { and metastasis }\end{array}$ & os & {$[35]$} \\
\hline & ISH & downexpression & $62 / 85(72.9 \%)$ & & & {$[102]$} \\
\hline & $\mathrm{IHC}$ & downexpression & $59 / 85(69.5 \%)$ & & & \\
\hline & Q-PCR & downexpression & $10 / 10(100 \%)$ & & & \\
\hline \multirow[t]{4}{*}{ Glioma } & RT-PCR, IHC & downexpression & $50 / 50(100 \%)$ & tumor grade & & {$[56]$} \\
\hline & WB, IHC & downexpression & $11 / 14(78.6 \%)$ & & & {$[78]$} \\
\hline & $\mathrm{IHC}$ & downexpression & $49 / 60(81.7 \%)$ & tumor grade & & [63] \\
\hline & RT-PCR & downexpression & $15 / 15(100 \%)$ & & & \\
\hline \multirow{4}{*}{$\begin{array}{l}\text { Head and neck } \\
\text { squamous cell } \\
\text { carcinomas }\end{array}$} & $\begin{array}{l}\text { RT-PCR, } \\
\text { sequencing }\end{array}$ & No mutation & $0 / 50$ & & & {$[27]$} \\
\hline & Q-PCR & downexpression & $38 / 50(76 \%)$ & & & \\
\hline & $\mathrm{IHC}$ & $\begin{array}{l}\text { Low nuclear ING4 } \\
\text { expression }\end{array}$ & $96 / 214(44.8 \%)$ & $\begin{array}{l}\text { differentiated status, } \mathrm{T} \\
\text { stage, and TNM stage }\end{array}$ & & {$[36]$} \\
\hline & $\mathrm{IHC}$ & $\begin{array}{l}\text { High cytoplasmic } \\
\text { ING4 expression }\end{array}$ & $143 / 214(66.8 \%)$ & $\begin{array}{l}\text { Lymph } \\
\text { node metastasis and } \\
14-3-3 \text { g expression }\end{array}$ & & \\
\hline \multirow[t]{3}{*}{$\begin{array}{l}\text { Hepatocellular } \\
\text { carcinoma }\end{array}$} & RT-PCR, WB & downexpression & $19 / 36(52.8 \%)$ & $\begin{array}{l}\text { Edmondson-Steiner } \\
\text { grade, vein invasion, } \\
\text { and microvessel } \\
\text { density. }\end{array}$ & $\begin{array}{l}\text { OS and } \\
\text { DFS }\end{array}$ & [29] \\
\hline & $\mathrm{IHC}$ & downexpression & $65 / 136(47.8 \%)$ & & & \\
\hline & WB & downexpression & $5 / 8(62.5 \%)$ & miR-650 expression & & [49] \\
\hline \multirow[t]{2}{*}{ Lung cancer } & SQ-PCR, WB & downexpression & $50 / 50(100 \%)$ & $\begin{array}{l}\text { Tumor grade (both } \\
\text { nuclear and } \\
\text { cytoplasmic ING4) }\end{array}$ & & {$[32]$} \\
\hline & $\mathrm{IHC}$ & $\begin{array}{l}\text { expression in the } \\
\text { cytoplasm higher } \\
\text { than in the } \\
\text { nucleus }\end{array}$ & $110 / 246(44.7 \%)$ & $\begin{array}{l}\text { Lymph node metastasis } \\
\text { (nuclear ING4) }\end{array}$ & & \\
\hline \multirow[t]{2}{*}{ Melanoma } & $\mathrm{IHC}$ & downexpression & $\begin{array}{l}33 \% \text { in primary } \\
\text { melanomas and } 47 \% \\
\text { in metastatic } \\
\text { melanomas }\end{array}$ & & & {$[84]$} \\
\hline & RT-PCR & downexpression & $10 / 17$ & & & {$[65]$} \\
\hline Ovarian cancer & RT-PCR & downexpression & $23 / 40(57.5 \%)$ & $\begin{array}{l}\text { tumor stage, } \\
\text { histological grade and } \\
\text { microvessel density }\end{array}$ & & {$[74]$} \\
\hline Prostate cancer & $\mathrm{IHC}$ & downexpression & $32 / 50(64 \%)$ & & & [44] \\
\hline
\end{tabular}

to ING4, such as TEL and p27KIP1 [40, 41]. Allelic loss of ING4 locus has been frequently found in head and neck squamous cell carcinomas and in breast tumors [18, 27]. In addition, point mutations of ING4 also contribute to the loss of ING4 function and tumorigenesis. The N214D mutant attenuated the ING4-mediated inhibition of cell proliferation, anchorageindependent growth, migration and induction of cell death, probably because the N214 residue is located in the conserved PHD domain, which is required for the recognition of H3K4me3 [42]. Interestingly, the altered ratio of nuclear and cytoplasmic ING4 expression 
can also be the reason for ING4 dysfunction and tumorigenesis. Nuclear expression of ING4 was gradually decreased from non-cancerous epithelium and dysplasia to head and neck squamous cell carcinoma (HNSCC), in contrast, cytoplasmic expression of ING4 was significantly increased in HNSCC [36].

The decreased expression of ING4 can also be attributed to the aberrant transcriptional regulation of ING4. Zhou et al. identified ING4 as well as other cell migration and adhesion genes including Tsp-1/THBS1, PVRL3, and PPAP2B, as direct targets of Myc in medulloblastoma cells using ChIP-chip analysis [43]. ING4 loss was required for Mycdependent prostate tumorigenesis in mice. Also, Pten loss could prevent differentiation by blocking ING4 expression [44]. In addition, cDNA Microarrays showed that ING4 was responsible to the human runt-related transcription factor 3 gene (RUNX3) upregulation in gastric cancer cells, but the molecular mechanisms was still unknown [45].

Post-transcriptional regulation also play important role in ING4 down-expression. Altered expression or mutation of splicing factors may cause a shift in the ratio of alternatively spliced isoforms, altering the ING4 splicing profiling of cancer cells. Raho et al. discovered four ING4 variants designated as ING4- $\Delta$ Ex2, $-\Delta$ Ex3, $-\Delta$ Ex6A and $-\Delta$ Ex6B in both normal and tumor tissues, which retained the nuclear localization and the ability to interact with p53 and HB01 complex. However, the ING4- $\Delta$ Ex6A variant, devoid of the C-terminal portion, lost the capability to inhibit NF- $\kappa B$ [14]. Li et al. also identified five novel aberrantly spliced variant forms of ING4_v1 and ING4_v2 which caused a deletion of the NLS or PHD domain contributing to the mislocalization of p53 and/or HAT/HDAC complexes in gastric adenocarcinoma [28]. Furthermore, accumulating evidence shows that microRNA (miRNA) represents an important post-transcriptional regulation mechanism for the inactivation of ING4 genes. For example, miR-214 promoted survival as well as gemcitabine resistance of pancreatic cancer cells partly through targeting ING4 [46]. MiR-650 has been reported to regulate ING4 in various cancers, including gastric, lung, hepatocellular and leukemic cancer cells [47-49]. Our previous work demonstrated that miR-650 conferred the docetaxel chemoresistance of lung adenocarcinoma (LAD) cells through directly targeting ING4, leading to increased cell apoptosis via regulating Bcl-2/Bax expression. Furthermore, miR650 expression was negatively correlated with response of LAD patients to docetaxel and served as an independent prognostic factor for LAD patients [50].

\section{Tumor suppressive functions}

Abundant evidence has supported the tumor suppressor role of ING proteins since their discovery. Interestingly, ING1 and ING2, ING4 and ING5 are respectively closely related in evolution and structure, indicating that they may have similar or complementary functions [1]. ING4 shares the capacity of chromatin modification and cell proliferation inhibition with other ING proteins, while it is worth highlighting its unique role in the regulation of angiogenesis and cell migration.

\section{Chromatin remodeling}

ING family proteins are involved in chromatin remodeling through interaction with histone modifiers such as histone acetyl transferase (HAT) and histone deacetylase (HDAC) complexes. For example, ING1 and ING2 are stable components of mSin3 HDAC complexes [51]. ING3 is a subunit of the Tip60/NuA4 HAT complexes [52]. ING5 associates with two distinct complexes containing HBO1 or nucleosomal H3-specific MOZ/MORF HATs [52]. ING4 is required for the HBO1/JADE histone acetyltransferases (HAT) to increase histone acetylation [52]. HBO1 and ING4 were bridged by Bromodomain-containing protein 1 (BRD1), a subunit of the MOZ/MORF H3 HAT, and the HBO1-BRD1-ING4 complex was crucial for transcriptional activation of erythroid developmental regulator genes [53]. Like other members of ING family, it directed these histone acetylation complexes to specific regions of the chromatin, through recognition of H3K4me3 via the highly conserved PHD finger [21, 
Fig. 2. Multiple modes of ING4 functions. (A) Nuclear and cytoplasmic interactors of ING4. In nucleus, ING4 may act in a general mode by which it regulates gene expression through bringing histone-modifying complexes to particular genomic regions by binding to specific DNA-binding proteins, leading to apoptosis, cell cycle arrest, suppression of angiogenesis and cell migration. In addition to its nuclear functions, cytoplasmic ING4 can interact with liprin a1 to regulate cell migration. (B) The interactors of ING4 targeting chromatin configuration. (a) ING4 physically interacts with p300, a member of histone acetyl transferase complexes, and p53, enhancing p53 acetylation and activating the p21/waf1 transcription. (b) ING4 enhances the p65HDAC-1 interactions, attenuating $\mathrm{NF}-\kappa \mathrm{B}$ activity and suppressing its target gene transcription. (c) ING4 interacts with the HIF-1-regulating key molecule HIF proly 1 hydroxylase 2 (HPH-2) to suppress HIF activity, but the precise mechanism is still not clear. $\mathrm{TF}$ = transcriptional factor; HAT = histone acetyltransferase; HDAC = histonte deacetylase).
A

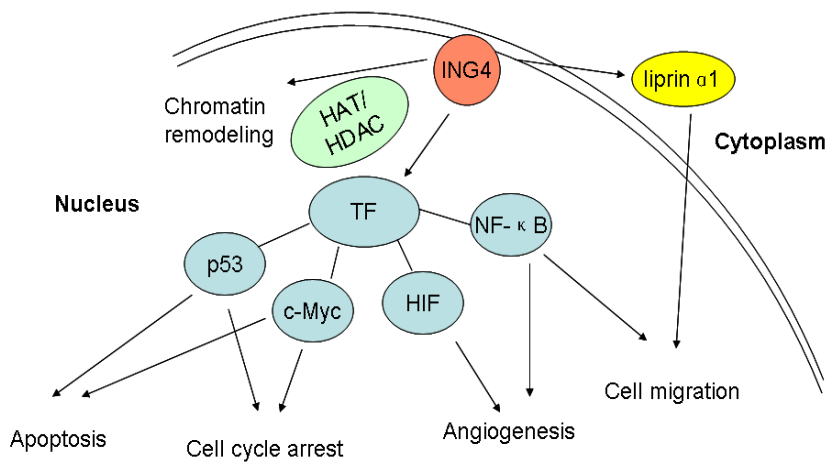

B

a.

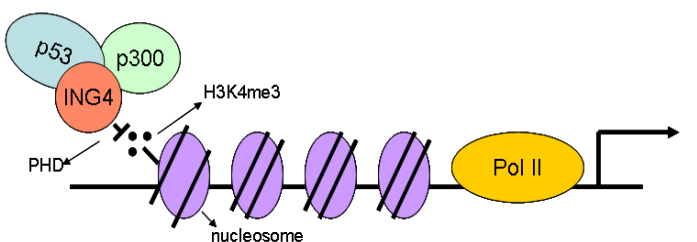

b.

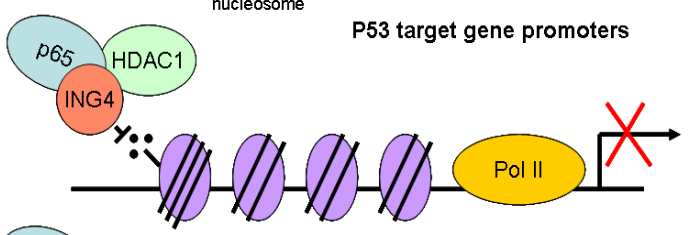

c.

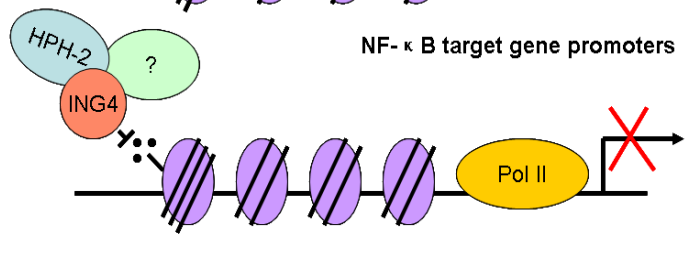

HIF-1 a target gene promoters

54]. The interaction between ING4 and H3K4me3 promoted HBO1 acetylation of histone H3, which was required for ING4-mediated cell death and inhibition of anchorage-independent growth [55].

ING4 have been described to associate with p53, the p65 subunit of the transcription factor NF- $\kappa \mathrm{B}$ and the hypoxia-inducible factor proly 1 hydroxylase 2 (HPH-2), resulting in enhancement of p53 transcriptional activity and repression of NF- $\kappa B$ and HIF responsive genes [7, 56-58]. These reports all point to an ING4 function model that ING4 may serve as a bridge to bring histone-modifying complexes to particular genomic regions by binding to specific DNA-binding proteins in response to various stresses, thus linking ING4 to chromatin remodeling function and gene expression regulation (Fig. 2B).

\section{Cell proliferation}

ING4 overexpression could suppress cell proliferation, induce cell cycle arrest and apoptosis, and enhance chemosensitivity in various cancers [7, 59-66]. An oncolytic HSV1716 that expresses ING4 (HSV1716Ing4) showed stronger oncolytic effect than HSV1716, highlighting the potent tumor-destructive ability of ING4 [67]. This anti-proliferation capacity is p53-dependent at least in part. ING4 and ING5 could increase p53 acetylation at lys-382 residue by interacting with p300, a component of HAT complexes, leading to p21/ WAF1 transcriptional activation and cell proliferation suppression, cell cycle arrest and apoptosis [7]. In glioma, curcumin was identified as an upstream regulator of ING4, inducing G2/M cell cycle arrest in a p53-dependent manner [68]. Interestingly, Epstein-Barr virus 
(EBV)-encoded EBNA3C, an essential transcriptional regulator for transforming primary B cells, could compete for the binding regions of ING4 with p53, thus blocking ING4-mediated p53 transcriptional activity and cell proliferation inhibition, suggesting ING4 was a possible target for some oncogenic viruses [69]. A recent research discovered that ING4 could regulate the proliferation and the secretory phenotype of primary non-transformed human fibroblasts, thus playing a critical role in the non-cell-autonomous regulation of tumor growth [62].

In addition, ING4 was shown to block Myc-induced loss of contact inhibition and breast cancer cells growth in vitro and in vivo, and the ING4 mutant exacerbated Myc-initiated mammary tumorigenesis by decreasing apoptosis and increasing metastasis, suggesting ING4 functioned to suppress Myc [18, 70]. ING4 might abolish the Myc translation and cell proliferation through interaction with a ribonucleoprotein AUF1 (AU-rich RNA-binding factor 1) [71]. In turn, ING4 could serve as a downstream modulator of Myc and PTEN in human prostate epithelial differentiation. PTEN-mediated loss of ING4 altered differentiation and promoted Myc-driven oncogenesis [44].

A recent research discovered that autophagy also contributed to ING4-induced glioma cell death in addition to apoptosis pathway [72]. Autophagy is an evolutionarily conserved process whereby the unnecessary or dysfunctional cellular components are degraded and recycled through the actions of lysosomes in responsive to cell nutritional starvation and other stressful stimuli. Basically, autophagy has been considered as an adaptive response to stress that sustains survival, whereas in some cases it can also lead to cell death and therefore is called Type II program cell death [73].

\section{Angiogenesis}

Reduced expression of ING4 in a mouse xenograft model of human glioblastoma cells could promote cancer cells grow and angiogenesis, suggesting that ING4 may act as a repressor of angiogenesis [56]. The correlation between ING4 and angiogenesis has been further confirmed in various cancers including ovarian cancer, colon cancer and breast cancer [74-77]. These functions depended on the interaction between ING4 and the nuclear factor NF- $\kappa \mathrm{B}$ in glioblastoma cells. ING4 could decrease NF- $\kappa \mathrm{B}$ binding activity as well as transcriptionally repress NF- $\kappa$ B-responsive genes, including IL-8, IL-6, COX-2, CSF-3 and many angiogenesis-related genes [56]. NF- $\kappa B$ is constitutively activated in many cancers and shown to facilitate tumorigenesis. Therefore, the suppression of NF- $\kappa B$ signaling pathway by ING4 indicates that ING4 is a candidate tumor suppressor and that its absence in tumors may allow inappropriately activation of NF- $\kappa B$ signaling and contribute to tumor growth. Nozell et al. further confirmed that ING4 could attenuate NF- $\mathrm{BB}$ activity at the target gene promoters through reducing p65 phosphorylation and the p65-p300 interactions to favor the p65-HDAC-1 interactions [78]. Macrophages isolated from ING4-null mice have reduced I $\kappa \mathrm{B}$ levels and increased nuclear RelA levels and NF- $\kappa \mathrm{B}$ promoter binding [79]. Hou et al. also found that ING4 could act as an E3 ubiquitin ligase to induce ubiquitination and degradation of p65, which is an additional mechanism to link ING4 to NF- $\kappa B$ [80]. In addition, ING4 was the upstream regulator of JWA, activating JWA promoter, inhibiting ILK and downstream NF- $\kappa B / I L-6 / S T A T 3 / V E G F$ signaling pathways, thus promoting melanoma angiogenesis [81]. In melanoma, ING4 was induced by BRMS1 (Breast cancer metastasis suppressor 1), a metastasis suppressor, and regulated angiogenesis through inhibiting NF- $\kappa B$ activity and IL-6 level [82].

In addition to NF- $\mathrm{KB}$, an interaction between ING4 and hypoxia inducible factor (HIF) has also been described, which played a key role in ING4-mediated suppression of MMinduced angiogenesis. ING4 was recruited by the HIF-1-regulating key molecule HIF proly 1 hydroxylase 2 (HPH-2) to HIF under hypoxic conditions, acting as a suppressor of HIF activity $[57,58,83]$. Evidence supports that ING4's mode of action in regulating HIF is also depend on its ability to recruit chromatin-remodeling factors [58]. However, further studies will be required to clarify the precise mechanism. 
Cell migration

ING4 has also been linked to the suppression of cell spreading, cell migration and contact inhibition. Li et al. found that ING4 expression was correlated with melanoma thickness, ulceration, as well as 5-year survival of patients with primary melanoma. In addition, ING4 overexpression could inhibit melanoma cell invasion through suppressing the activity of the small GTPase RhoA, the Rho kinase ROCK as well as MMP-2 and MMP9 [84]. Many of these invasion-related genes such as MMPs are known to be regulated by NF- $\kappa \mathrm{B}$ [85]. A significant negative correlation between expression of nuclear p65, MMP-9 and ING4 was observed in human astrocytomas, and the reduction of ING4 expression was related to higher histologic grades [31]. ING4 could repress the expression of NF-kB-target genes including IL6, IL8, and PTGS2, leading to attenuated cell migration in breast cancer cells [37]. Similarly, adenovirus-mediated ING4 expression contributed to suppression of lung carcinoma cell invasion and metastasis [86]. In addition, Shen et al. demonstrated that liprin a1/PPFIA1, a cytoplasmic protein necessary for focal adhesion formation and axon guidance, was required for ING4-mediated regulation of cell migration, thus increasing our knowledge on the function of cytoplasmic ING4 [87]. However, ING4 variants seemed to have different effect of cell migration suppression and different binding affinities to liprin a1 and G3BP2a [13]. Recently, ING4 has been proposed to mediate the regulation of melanoma cells migration by KAI/CD82 transmembrane protein [88].

\section{ING4 in cancer therapy}

Gene therapy has emerged as a novel promising cancer therapy in recent years. Furthermore, gene therapy combined with conventional anti-cancer strategies has been explored to achieve greater therapeutic benefit while reducing the treatment toxicity and resistance. Since ING4 has been demonstrated to play an important role in suppression of tumorigenesis, it is considered a valuable target for molecular therapy alone or combined with radio- or chemotherapy. Adenovirus-mediated ING4 (Ad-ING4) gene transfer could induce growth inhibition and apoptosis in human lung, pancreatic and breast cancer cells $[60,86,89]$. Furthermore, Ad-ING4 plus cisplatin combined treatment resulted in synergistic growth inhibition, enhanced apoptosis and reduced tumor vessel CD34 expression and microvessel density (MVD) in hepatocarcinoma cells [90]. This combined treatment could also reverse multidrug resistance and induce apoptosis of cisplatin-resistant gastric cancer cells in vitro and in vivo [91]. ING4 was also involved in the regulation of docetaxel (DTX) sensitivity in human lung adenocarcinoma (LAD). The molecular mechanism was associated with ING4-induced apoptosis enhancement and G2/M arrest, and miR-650 was identified as its upstream regulator. Furthermore, ING4 expression was inversely correlated with miR650, and both of their expression levels were correlated with tumor response to DTX and the prognosis of LAD patients $[50,92]$. These results have underlined ING4 is a potential molecular target for overcoming resistance to DTX-based chemotherapies in LAD.

Radiotherapy is also an effective measures commonly used for cancer treatment, but the normal tissue radiation injury and the radioresistance remain major challenges that limit its clinical application [93]. Gene therapy can improve the effect of radiation therapy by increasing the cytotoxicity that selectively targets cancer cells and enhancing the radiosensitivity of cancer cells [94]. Therefore, targeting gene therapy combined with radiotherapy has become a novel mode of cancer therapy. Ad-ING4 combined with (125) I radiotherapy treatment had a synergistic tumor-suppressive effect by inducing apoptosis and inhibiting proliferation in pancreatic cancer cells, and inhibiting angiogenesis in pancreatic cancer xenografted tumors [95]. It could also restore the radiosensitivity of NSCLC cells [96]. Extensive studies have shown that IL-24 displays ubiquitous antitumor property and tumor-specific killing activity [97]. ING4/IL-24 bicistronic adenovirus (Ad-ING4-IL-24) combination treatment was shown to have a synergistic tumor-suppressive capacity in NSCLC, breast cancer and hepatocarcinoma and promote radiosensitivity of breast cancer cells [98-101].

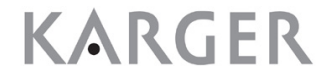




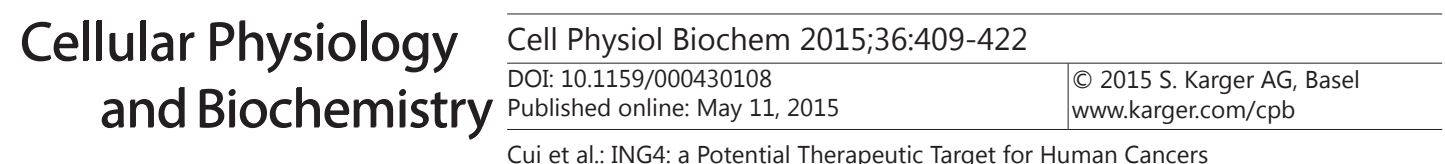

\section{Conclusion and future directions}

Although ING4 has not been identified until very recent years, it has emerged to be a potent tumor suppressor of ING family. ING4 can regulate chromatin modification through their interaction with HAT or HDAC. It can also significantly suppress tumor growth through inducing apoptosis and cell cycle arrest. In addition, it has been proposed to inhibit tumor angiogenesis and cell migration. Evidence has shown that the ING4 functions are mediated by some important signaling pathways such as p53, NF- $\kappa B$ and HIF-1. However, other candidate mechanisms are also described to be involved in ING4-mediated suppression of tumorigenesis. Therefore, further studies are still warranted to better dissect the mechanisms by which ING4 exerts its functions. Alterations in protein levels or localization of ING4 have been commonly observed in cancers, which contribute to tumor progression and poor prognosis, but little is known about the underlying mechanisms. Given that recent work has substantiated the role of ING4 as a potent tumor suppressor, the ING4-based gene therapy has been developed. Adenovirus-mediated ING4 reintroduction has been shown to inhibit tumor growth, invasion and angiogenesis. When combined with radiation or specific chemotherapy, ING4 can also enhance the radio- and chemosensitivity of cancer cells. Therefore, ING4-based gene therapy represents a promising strategy, but its clinical application still needs further investigations.

\section{Acknowledgements}

The work was supported by grants from the National Natural Science Foundation of China (No.81172335 and 81472266) and the Excellent Youth Foundation of Jiangsu Province, China (BK20140032). We apologize to all colleagues whose relevant contributions could not be cited due to space limitations.

\section{Disclosure Statement}

The authors declare that they have no conflicts of interest related to this work.

\section{References}

1 He GH, Helbing CC, Wagner MJ, Sensen CW, Riabowol K: Phylogenetic analysis of the ING family of PHD finger proteins. Mol Biol Evol 2005;22:104-116.

2 Loewith R, Meijer M, Lees-Miller SP, Riabowol K, Young D: Three yeast proteins related to the human candidate tumor suppressor p33 (ING1) are associated with histone acetyltransferase activities. Mol Cell Biol 2000;20:3807-3816.

3 Garkavtsev I, Kazarov A, Gudkov A, Riabowol K: Suppression of the novel growth inhibitor p33ING1 promotes neoplastic transformation. Nat Genet 1996;14:415-420.

4 Garkavtsev I, Grigorian IA, Ossovskaya VS, Chernov MV, Chumakov PM, Gudkov AV: The candidate tumour suppressor p33ING1 cooperates with p53 in cell growth control. Nature 1998;391:295-298.

5 Nagashima M, Shiseki M, Miura K, Hagiwara K, Linke SP, Pedeux R, Wang XW, Yokota J, Riabowol K, Harris CC: DNA damage-inducible gene p33ING2 negatively regulates cell proliferation through acetylation of p53. Proc Natl Acad Sci U S A 2001;98:9671-9676.

6 Nagashima M, Shiseki M, Pedeux RM, Okamura S, Kitahama-Shiseki M, Miura K, Yokota J, Harris CC: A novel PHD-finger motif protein, p47ING3, modulates p53-mediated transcription, cell cycle control, and apoptosis. Oncogene 2003;22:343-350.

7 Shiseki M, Nagashima M, Pedeux RM, Kitahama-Shiseki M, Miura K, Okamura S, Onogi H, Higashimoto Y, Appella E, Yokota J, Harris CC: p29ING4 and p28ING5 bind to p53 and p300, and enhance p53 activity. Cancer Res 2003;63:2373-2378. 
8 Soliman MA, Berardi P, Pastyryeva S, Bonnefin P, Feng X, Colina A, Young D, Riabowol K.l: ING1a expression increases during replicative senescence and induces a senescent phenotype. Aging Cell 2008;7:783-794.

9 Cheung KJ, Jr., Mitchell D, Lin P, Li G: The tumor suppressor candidate p33(ING1) mediates repair of UVdamaged DNA. Cancer Res 2001;61:4974-4977.

10 Scott M, Bonnefin P, Vieyra D, Boisvert FM, Young D, Bazett-Jones DP, Riabowol K: UV-induced binding of ING1 to PCNA regulates the induction of apoptosis. J Cell Sci 2001;114:3455-3462.

11 Wang J, Chin MY, Li G: The novel tumor suppressor p33ING2 enhances nucleotide excision repair via inducement of histone H4 acetylation and chromatin relaxation. Cancer Res 2006;66:1906-1911.

12 Larrieu D, Ythier D, Binet R, Brambilla C, Brambilla E, Sengupta S, Pedeux R: ING2 controls the progression of DNA replication forks to maintain genome stability. EMBO Rep 2009;10:1168-1174.

13 Unoki M, Shen JC, Zheng ZM, Harris CC: Novel splice variants of ING4 and their possible roles in the regulation of cell growth and motility. J Biol Chem 2006;281:34677-34686.

14 Raho G, Miranda C, Tamborini E, Pierotti MA, Greco A: Detection of novel mRNA splice variants of human ING4 tumor suppressor gene. Oncogene 2007;26:5247-5257.

15 Tsai KW, Lin WC: Quantitative analysis of wobble splicing indicates that it is not tissue specific. Genomics 2006;88:855-864.

16 Zhang X, Wang KS, Wang ZQ, Xu LS, Wang QW, Chen F, Wei DZ, Han ZG: Nuclear localization signal of ING4 plays a key role in its binding to p53. Biochem Biophys Res Commun 2005;331:1032-1038.

17 Unoki M, Kumamoto K, Takenoshita S, Harris CC: Reviewing the current classification of inhibitor of growth family proteins. Cancer Sci 2009;100: 1173-1179.

18 Kim S, Chin K, Gray JW, Bishop JM: A screen for genes that suppress loss of contact inhibition: identification of ING4 as a candidate tumor suppressor gene in human cancer. Proc Natl Acad Sci U S A 2004;101:1625116256.

19 Bienz M: The PHD finger, a nuclear protein-interaction domain. Trends Biochem Sci 2006;31:35-40.

20 Peña PV, Davrazou F, Shi X, Walter KL, Verkhusha VV, Gozani O, Zhao R, Kutateladze TG: Molecular mechanism of histone H3K4me3 recognition by plant homeodomain of ING2. Nature 2006;442:100-103.

21 Palacios A, Muñoz IG, Pantoja-Uceda D, Marcaida MJ, Torres D, Martín-García JM, Luque I, Montoya G, Blanco FJ: Molecular basis of histone H3K4me3 recognition by ING4. J Biol Chem 2008;283:15956-15964.

22 Santos-Rosa H, Schneider R, Bannister AJ, Sherriff J, Bernstein BE, Emre NC, Schreiber SL, Mellor J, Kouzarides T: Active genes are tri-methylated at K4 of histone H3. Nature 2002;419:407-411.

23 Scott M, Boisvert FM, Vieyra D, Johnston RN, Bazett-Jones DP, Riabowol K: UV induces nucleolar translocation of ING1 through two distinct nucleolar targeting sequences. Nucleic Acids Res 2001;29:20522058.

24 Han X, Feng X, Rattner JB, Smith H, Bose P, Suzuki K, Soliman MA, Scott MS, Burke BE, Riabowol K: Tethering by lamin A stabilizes and targets the ING1 tumour suppressor. Nat Cell Biol 2008;10:1333-1340.

25 Wang Y, Wang J, Li G: Leucine zipper-like domain is required for tumor suppressor ING2-mediated nucleotide excision repair and apoptosis. FEBS Lett 2006;580:3787-3793.

26 Palacios A, Moreno A, Oliveira BL, Rivera T, Prieto J, García P, Fernández-Fernández MR, Bernadó P, Palmero I, Blanco FJ: The dimeric structure and the bivalent recognition of H3K4me3 by the tumor suppressor ING4 suggests a mechanism for enhanced targeting of the HBO1 complex to chromatin. J Mol Biol 2010;396:1117-1127.

27 Gunduz M, Nagatsuka H, Demircan K, Gunduz E, Cengiz B, Ouchida M, Tsujigiwa H, Yamachika E, Fukushima K, Beder L, Hirohata S, Ninomiya Y, Nishizaki K, Shimizu K, Nagai N: Frequent deletion and down-regulation of ING4, a candidate tumor suppressor gene at $12 \mathrm{p} 13$, in head and neck squamous cell carcinomas. Gene 2005;356:109-117.

28 Li M, Jin Y, Sun WJ, Yu Y, Bai J, Tong DD, Qi JP, Du JR, Geng JS, Huang Q, Huang XY, Huang Y, Han FF, Meng XN, Rosales JL, Lee KY, Fu SB: Reduced expression and novel splice variants of ING4 in human gastric adenocarcinoma. J Pathol 2009;219:87-95.

29 Fang F, Luo LB, Tao YM, Wu F, Yang LY: Decreased expression of inhibitor of growth 4 correlated with poor prognosis of hepatocellular carcinoma. Cancer Epidemiol Biomarkers Prev 2009;18:409-416.

30 Borkosky SS, Gunduz M, Beder L, Tsujigiwa H, Tamamura R, Gunduz E, Katase N, Rodriguez AP, Sasaki A, Nagai N, Nagatsuka H: Allelic loss of the ING gene family loci is a frequent event in ameloblastoma. Oncol Res 2010;18:509-518. 
31 Klironomos G, Bravou V, Papachristou DJ, Gatzounis G, Varakis J, Parassi E, Repanti M, Papadaki H: Loss of inhibitor of growth (ING-4) is implicated in the pathogenesis and progression of human astrocytomas. Brain Pathol 2010;20: 490-497.

32 Wang QS, Li M, Zhang LY, Jin Y, Tong DD, Yu Y, Bai J, Huang Q, Liu FL, Liu A, Lee KY, Fu SB: Down-regulation of ING4 is associated with initiation and progression of lung cancer. Histopathology 2010;57:271-281.

33 Tapia C, Zlobec I, Schneider S, Kilic E, Güth U, Bubendorf L, Kim S: Deletion of the inhibitor of growth 4 (ING4) tumor suppressor gene is prevalent in human epidermal growth factor 2 (HER2)-positive breast cancer. Hum Pathol 2011;42: 983-990.

34 You Q Wang XS, Fu SB, Jin XM: Downregulated expression of inhibitor of growth 4 (ING4) in advanced colorectal cancers: a non-randomized experimental study. Pathology oncology research : POR 2011;17:473-477.

35 Nanding A, Tang L, Cai L, Chen H, Geng J, Liu X, Ning X, Li X, Zhang Q: Low ING4 protein expression detected by paraffin-section immunohistochemistry is associated with poor prognosis in untreated patients with gastrointestinal stromal tumors. Gastric cancer : official journal of the International Gastric Cancer Association and the Japanese Gastric Cancer Association 2014;17:87-96.

36 Li XH, Kikuchi K, Zheng Y, Noguchi A, Takahashi H, Nishida T, Masuda S, Yang XH, Takano Y: Downregulation and translocation of nuclear ING4 is correlated with tumorigenesis and progression of head and neck squamous cell carcinoma. Oral Oncol 2011;47:217-223.

37 Byron SA, Min E, Thal TS, Hostetter G, Watanabe AT, Azorsa DO, Little TH, Tapia C, Kim S: Negative regulation of NF-kappaB by the ING4 tumor suppressor in breast cancer. PLoS One 2012;7:e46823.

38 Guerillon C, Bigot N, Pedeux R: The ING tumor suppressor genes: Status in human tumors. Cancer Lett 2014;345:1-16.

39 Zhang G, Li G: Novel multiple markers to distinguish melanoma from dysplastic nevi. PLoS One 2012;7:e45037.

40 Raynaud S, Cave H, Baens M, Bastard C, Cacheux V, Grosgeorge J, Guidal-Giroux C, Guo C, Vilmer E, Marynen P, Grandchamp B: The 12;21 translocation involving TEL and deletion of the other TEL allele: two frequently associated alterations found in childhood acute lymphoblastic leukemia. Blood 1996;87:28912899.

41 Cavé H, Gérard B, Martin E, Guidal C, Devaux I, Weissenbach J, Elion J, Vilmer E, Grandchamp B: Loss of heterozygosity in the chromosomal region 12p12-13 is very common in childhood acute lymphoblastic leukemia and permits the precise localization of a tumor-suppressor gene distinct from p27KIP1. Blood 1995;86:3869-3875.

42 Moreno A, Palacios A, Orgaz JL, Jimenez B, Blanco FJ, Palmero I: Functional impact of cancer-associated mutations in the tumor suppressor protein ING4. Carcinogenesis 2010;31:1932-1938.

43 Zhou L, Picard D, Ra YS, Li M, Northcott PA, Hu Y, Stearns D, Hawkins C, Taylor MD, Rutka J, Der SD, Huang A : Silencing of thrombospondin-1 is critical for myc-induced metastatic phenotypes in medulloblastoma. Cancer Res 2010;70:8199-8210.

44 Berger PL, Frank SB, Schulz VV, Nollet EA, Edick MJ, Holly B, Chang TT, Hostetter G, Kim S, Miranti CK: Transient Induction of ING4 by Myc Drives Prostate Epithelial Cell Differentiation and Its Disruption Drives Prostate Tumorigenesis. Cancer Res 2014;74:3357-3368.

45 Nagahama Y, Ishimaru M, Osaki M, Inoue T, Maeda A, Nakada C, Moriyama M, Sato K, Oshimura M, Ito H: Apoptotic pathway induced by transduction of RUNX3 in the human gastric carcinoma cell line MKN-1. Cancer Sci 2008;99: 23-30.

46 Zhang XJ, Ye H, Zeng CW, He B, Zhang H, Chen YQ: Dysregulation of miR-15a and miR-214 in human pancreatic cancer. J Hematol Oncol 2010;3:46.

47 Zhang X, Zhu W, Zhang J, Huo S, Zhou L, Gu Z, Zhang M: MicroRNA-650 targets ING4 to promote gastric cancer tumorigenicity. Biochem Biophys Res Commun 2010;395:275-280.

48 Mraz M, Dolezalova D, Plevova K, Stano Kozubik K, Mayerova V, Cerna K, Musilova K, Tichy B, Pavlova S, Borsky M, Verner J, Doubek M, Brychtova Y, Trbusek M, Hampl A, Mayer J, Pospisilova S: MicroRNA-650 expression is influenced by immunoglobulin gene rearrangement and affects the biology of chronic lymphocytic leukemia. Blood 2012;119:2110-2113.

49 Zeng ZL, Li FJ, Gao F, Sun DS, Yao L: Upregulation of miR-650 is correlated with down-regulation of ING4 and progression of hepatocellular carcinoma. J Surg Oncol 2013;107:105-110. 
50 Huang JY, Cui SY, Chen YT, Song HZ, Huang GC, Feng B, Sun M, De W, Wang R, Chen LB: MicroRNA-650 was a prognostic factor in human lung adenocarcinoma and confers the docetaxel chemoresistance of lung adenocarcinoma cells via regulating Bcl-2/Bax expression. PLoS One 2013;8;e72615.

51 Kuzmichev A, Zhang Y, Erdjument-Bromage H, Tempst P, Reinberg D: Role of the Sin3-histone deacetylase complex in growth regulation by the candidate tumor suppressor p33(ING1). Mol Cell Biol 2002;22:835848.

52 Kuzmichev A, Zhang Y, Erdjument-Bromage H, Tempst P, Reinberg D: ING tumor suppressor proteins are critical regulators of chromatin acetylation required for genome expression and perpetuation. Mol Cell 2006;21:51-64.

53 Mishima Y, Miyagi S, Saraya A, Negishi M, Endoh M, Endo TA, Toyoda T, Shinga J, Katsumoto T, Chiba T, Yamaguchi N, Kitabayashi I, Koseki H, Iwama A: The Hbo1-Brd1/Brpf2 complex is responsible for global acetylation of H3K14 and required for fetal liver erythropoiesis. Blood 2011;118:2443-2453.

54 Saksouk N, Avvakumov N, Champagne KS, Hung T, Doyon Y, Cayrou C, Paquet E, Ullah M, Landry AJ, Côté V, Yang XJ, Gozani O, Kutateladze TG, Côté J: HBO1 HAT complexes target chromatin throughout gene coding regions via multiple PHD finger interactions with histone H3 tail. Mol Cell 2009;33:257-265.

55 Hung T, Binda O, Champagne KS, Kuo AJ, Johnson K, Chang HY, Simon MD, Kutateladze TG, Gozani O: ING4 mediates crosstalk between histone H3 K4 trimethylation and H3 acetylation to attenuate cellular transformation. Mol Cell 2009;33:248-256.

56 Garkavtsev I, Kozin SV, Chernova O, Xu L, Winkler F, Brown E, Barnett GH, Jain RK: The candidate tumour suppressor protein ING4 regulates brain tumour growth and angiogenesis. Nature 2004;428:328-332.

57 Ozer A, Bruick RK: Regulation of HIF by prolyl hydroxylases: recruitment of the candidate tumor suppressor protein ING4. Cell Cycle 2005;4:1153-1156.

58 Ozer A, Wu LC, Bruick RK: The candidate tumor suppressor ING4 represses activation of the hypoxia inducible factor (HIF). Proc Natl Acad Sci U S A 2005;102:7481-7486.

59 Zhang X, Xu LS, Wang ZQ Wang KS, Li N, Cheng ZH, Huang SZ, Wei DZ, Han ZG: ING4 induces G2/M cell cycle arrest and enhances the chemosensitivity to DNA-damage agents in HepG2 cells. FEBS Lett 2004;570:7-12.

60 Li Z, Xie Y, Sheng W, Miao J, Xiang J, Yang J: Tumor-suppressive effect of adenovirus-mediated inhibitor of growth 4 gene transfer in breast carcinoma cells in vitro and in vivo. Cancer Biother Radiopharm 2010;25:427-437.

61 Wei Q He W, Lu Y, Yao J, Cao X: Effect of the tumor suppressor gene ING4 on the proliferation of MCF-7 human breast cancer cells. Oncology letters 2012;4:438-442.

62 Moreno A, Soleto I, Garcia-Sanz P, Moreno-Bueno G, Palmero I: ING4 regulates a secretory phenotype in primary fibroblasts with dual effects on cell proliferation and tumor growth. Oncogene 2014;33:19451953.

63 Li X, Cai L, Chen H, Zhang Q, Zhang S, Wang Y, Dong Y, Cheng H, Qi J: Inhibitor of growth 4 induces growth suppression and apoptosis in glioma U87MG, Pathobiology 2009;76:181-192.

64 Li X, Zhang Q, Cai L, Wang Y, Wang Q, Huang X, Fu S, Bai J, Liu J, Zhang G, Qi J: Inhibitor of growth 4 induces apoptosis in human lung adenocarcinoma cell line A549 via Bcl-2 family proteins and mitochondria apoptosis pathway. J Cancer Res Clin Oncol 2009;135;829-835.

65 Cai L, Li X, Zheng S, Wang Y, Wang Y, Li H, Yang J, Sun J: Inhibitor of growth 4 is involved in melanomagenesis and induces growth suppression and apoptosis in melanoma cell line M14. Melanoma research 2009;19:1-7.

66 Li X, Cai L, Liang M, Wang Y, Yang J, Zhao Y: ING4 induces cell growth inhibition in human lung adenocarcinoma A549 cells by means of Wnt-1/beta-catenin signaling pathway. Anatomical record 2008;291:593-600.

67 Conner J, Braidwood L: Expression of inhibitor of growth 4 by HSV1716 improves oncolytic potency and enhances efficacy. Cancer Gene Ther 2012;19:499-507.

68 Liu E, Wu J, Cao W, Zhang J, Liu W, Jiang X, Zhang X: Curcumin induces G2/M cell cycle arrest in a p53dependent manner and upregulates ING4 expression in human glioma. J Neurooncol 2007;85:263-270.

69 Saha A, Bamidele A, Murakami M, Robertson ES: EBNA3C attenuates the function of p53 through interaction with inhibitor of growth family proteins 4 and 5. J Virol 2011;85:2079-2088.

70 Kim S, Welm AL, Bishop JM: A dominant mutant allele of the ING4 tumor suppressor found in human cancer cells exacerbates MYC-initiated mouse mammary tumorigenesis. Cancer Res 2010;70:5155-5162. 
71 Lu M, Pan C, Zhang L, Ding C, Chen F, Wang Q, Wang K, Zhang X: ING4 inhibits the translation of protooncogene MYC by interacting with AUF1. FEBS Lett 2013;587:1597-1604.

72 Gong A, Ye S, Xiong E, Guo W, Zhang Y, Peng W, Shao G, Jin J, Zhang Z, Yang J, Gao J: Autophagy contributes to ING4-induced glioma cell death. Exp Cell Res 2013;319:1714-1723.

73 Hotchkiss RS, Strasser A, Mcdunn JE, Swanson PE: Cell death. N Engl J Med 2009;361:1570-1583.

74 Liu Y, Yu L, Wang Y, Zhang Y, Wang Y, Zhang G: Expression of tumor suppressor gene ING4 in ovarian carcinoma is correlated with microvessel density. J Cancer Res Clin Oncol 2012;138:647-655.

75 Lou C, Jiang S, Guo X, Dong XS: ING4 is negatively correlated with microvessel density in colon cancer. Tumour Biol 2012;33:2357-2364.

76 Zhang L, Wang Y, Zhang F, Wang Y, Zhang Q: Correlation between tumor suppressor inhibitor of growth family member 4 expression and microvessel density in breast cancer. Hum Pathol 2012;43:1611-1617.

77 Xu M, Xie Y, Sheng W, Miao J, Yang J: Adenovirus-mediated ING4 Gene Transfer in Osteosarcoma Suppresses Tumor Growth via Induction of Apoptosis and Inhibition of Tumor Angiogenesis. Technol Cancer Res Treat. 2014 Oct 16. ii: 1533034614500424. [Epub ahead of print]

78 Nozell S, Laver T, Moseley D, Nowoslawski L, De Vos M, Atkinson GP, Harrison K, Nabors LB, Benveniste EN: The ING4 tumor suppressor attenuates NF-kappaB activity at the promoters of target genes. Mol Cell Biol 2008;28:6632-6645.

79 Coles AH, Gannon H, Cerny A, Kurt-Jones E, Jones SN : Inhibitor of growth-4 promotes IkappaB promoter activation to suppress NF-kappaB signaling and innate immunity. Proc Natl Acad Sci U S A 2010;107:11423-11428.

80 Hou Y, Zhang Z, Xu Q, Wang H, Xu Y, Chen K: Inhibitor of growth 4 induces NFkappaB/p65 ubiquitindependent degradation. Oncogene 2014;33:1997-2003.

81 Lu J, Tang Y, Cheng Y, Zhang G, Yip A, Martinka M, Dong Z, Zhou J, Li G: ING4 regulates JWA in angiogenesis and their prognostic value in melanoma patients. Br J Cancer 2013;109:2842-2852.

$82 \mathrm{Li} \mathrm{J,} \mathrm{Li} \mathrm{G:} \mathrm{Cell} \mathrm{cycle} \mathrm{regulator} \mathrm{ING4} \mathrm{is} \mathrm{a} \mathrm{suppressor} \mathrm{of} \mathrm{melanoma} \mathrm{angiogenesis} \mathrm{that} \mathrm{is} \mathrm{regulated} \mathrm{by} \mathrm{the}$ metastasis suppressor BRMS1. Cancer Res 2010;70:10445-10453.

83 Colla S, Tagliaferri S, Morandi F, Lunghi P, Donofrio G, Martorana D, Mancini C, Lazzaretti M, Mazzera L, Ravanetti L, Bonomini S, Ferrari L, Miranda C, Ladetto M, Neri TM, Neri A, Greco A, Mangoni M, Bonati A, Rizzoli V, Giuliani N: The new tumor-suppressor gene inhibitor of growth family member 4 (ING4) regulates the production of proangiogenic molecules by myeloma cells and suppresses hypoxiainducible factor-1 alpha (HIF-1alpha) activity: involvement in myeloma-induced angiogenesis. Blood 2007;110:4464-4475.

84 Li J, Martinka M, Li G: Role of ING4 in human melanoma cell migration, invasion and patient survival. Carcinogenesis 2008;29:1373-1379.

85 Aggarwal BB, Shishodia S, Sandur SK, Pandey MK, Sethi G: Inflammation and cancer: how hot is the link? Biochem Pharmacol 2006;72:1605-1621.

86 Xie Y, Zhang H, Sheng W, Xiang J, Ye Z, Yang J: Adenovirus-mediated ING4 expression suppresses lung carcinoma cell growth via induction of cell cycle alteration and apoptosis and inhibition of tumor invasion and angiogenesis. Cancer Lett 2008;271:105-116.

87 Shen JC, Unoki M, Ythier D, Duperray A, Varticovski L, Kumamoto K, Pedeux R, Harris CC: Inhibitor of growth 4 suppresses cell spreading and cell migration by interacting with a novel binding partner, liprin alpha1. Cancer Res 2007;67: 2552-2558.

88 Tang Y, Cheng Y, Martinka M, Ong CJ, Li G: Prognostic significance of KAI1/CD82 in human melanoma and its role in cell migration and invasion through the regulation of ING4. Carcinogenesis 2014;35:86-95.

89 Xie YF, Sheng W, Xiang J, Zhang H, Ye Z, Yang J: Adenovirus-mediated ING4 expression suppresses pancreatic carcinoma cell growth via induction of cell-cycle alteration, apoptosis, and inhibition of tumor angiogenesis. Cancer Biother Radiopharm 2009;24:261-269.

90 Xie Y, Sheng W, Miao J, Xiang J, Yang J: Enhanced antitumor activity by combining an adenovirus harboring ING4 with cisplatin for hepatocarcinoma cells. Cancer Gene Ther 2011;18:176-188.

91 Mao ZL, He SB, Sheng WH, Dong XQ, Yang JC: Adenovirus-mediated ING4 expression reduces multidrug resistance of human gastric carcinoma cells in vitro and in vivo. Oncol Rep 2013;30:2187-2194.

92 Wang R, Huang J, Feng B, De W, Chen L: Identification of ING4 (inhibitor of growth 4) as a modulator of docetaxel sensitivity in human lung adenocarcinoma. Mol Med 2012;18:874-886. 


\section{Cellular Physiology Cell Physiol Biochem 2015;36:409-422 \begin{tabular}{ll|l} 
DOI: 10.1159/000430108 & O 2015 S. Karger AG, Basel \\
and & ww.karger.com/cpb
\end{tabular} \\ Cui et al.: ING4: a Potential Therapeutic Target for Human Cancers}

93 Chargari C, Clemenson C, Martins I, Perfettini JL, Deutsch E: Understanding the functions of tumor stroma in resistance to ionizing radiation: emerging targets for pharmacological modulation. Drug Resist Updat 2013;16:10-21.

94 Dutreix M, Cosset JM, Sun JS: Molecular therapy in support to radiotherapy. Mutat Res 2010;704:182-189.

95 Zhao Y, Su C, Zhai H, Tian Y, Sheng W, Miao J, Yang J: Synergistic antitumor effect of adenovirus-mediated hING4 gene therapy and (125)I radiation therapy on pancreatic cancer. Cancer Lett 2012;316:211-218.

96 Ling C, Xie Y, Zhao D, Zhu Y, Xiang J, Yang J: Enhanced radiosensitivity of non-small-cell lung cancer (NSCLC) by adenovirus-mediated ING4 gene therapy. Cancer Gene Ther 2012;19:697-706.

97 Lebedeva IV, Emdad L, Su ZZ, Gupta P, Sauane M, Sarkar D, Staudt MR, Liu SJ, Taher MM, Xiao R, Barral P, Lee SG, Wang D, Vozhilla N, Park ES, Chatman L, Boukerche H, Ramesh R, Inoue S, Chada S, Li R, De Pass AL, Mahasreshti PJ, Dmitriev IP, Curiel DT, Yacoub A, Grant S, Dent P, Senzer N, Nemunaitis JJ, Fisher PB: mda7/IL-24, novel anticancer cytokine: focus on bystander antitumor, radiosensitization and antiangiogenic properties and overview of the phase I clinical experience (Review). Int J Oncol 2007;31:985-1007.

98 Zhu Y, Lv H, Xie Y, Sheng W, Xiang J, Yang J: Enhanced tumor suppression by an ING4/IL-24 bicistronic adenovirus-mediated gene cotransfer in human non-small cell lung cancer cells. Cancer Gene Ther 2011;18:627-636.

99 Xie Y, Lv H, Sheng W, Miao J, Xiang J, Yang J: Synergistic tumor suppression by adenovirus-mediated inhibitor of growth 4 and interleukin-24 gene cotransfer in hepatocarcinoma cells. Cancer Biother Radiopharm 2011;26:681-695.

100 Zhao Y, Li Z, Sheng W, Miao J, Yang J. Adenovirus-mediated ING4/IL-24 double tumor suppressor gene cotransfer enhances antitumor activity in human breast cancer cells. Oncol Rep 2012;28:1315-1324.

101 Zhao Y, Li Z, Sheng W, Miao J, Yang J: Radiosensitivity by ING4-IL-24 bicistronic adenovirus-mediated gene cotransfer on human breast cancer cells. Cancer Gene Ther 2013;20:38-45.

102 Li S, Fan T, Liu H, Chen J, Qin C, Ren X: Tumor suppressor ING4 overexpression contributes to proliferation and invasion inhibition in gastric carcinoma by suppressing the NF-kappaB signaling pathway. Mol Biol Rep 2013;40:5723-5732. 